\title{
Editorial
}

\section{Time to lift the veil of secrecy}

This issue of the International Journal of Risk and Safety in Medicine contains several papers on the subject of the secrecy which surrounds drug regulation. What emerges from the articles is a complex picture of how secrecy, together with its ugly sisters lack of transparency and lack of accountability, can distort and undermine the prime function of drug regulation which is to serve the public and protect health. Much of the material in these papers was discussed at an international seminar ${ }^{1}$ which examined the origins, scope and effects of secrecy in drug regulation and considered ways of promoting increased openness and accountability.

Secrecy in medicine can be traced back to jealously guarded secrets and the power of patent remedies but it has extended into almost all aspects of the development, regulation and surveillance of medicines. Various factors are identified which help to perpetuate and justify secrecy: the belief that people do not need or cannot cope with knowledge; bureaucratic inertia; lack of capacity in agencies; lack of a legal obligation to inform; and pressure from manufacturers. All of these reasons help to explain the thick veil of secrecy which surrounds medicines and this multiplicity of causal factors also helps to explain why it is so difficult to lift the veil and throw light on decisions which help to determine the way in which modern therapeutic medicine is practised. Some of the papers in this issue focus on secrecy in relation to a particular drug or one country while other papers take a broader look comparing access to information in selected countries or considering the implications of global harmonisation initiatives. The common message which emerges is that the time has come to end this long standing tradition of secrecy, for without information and transparent decision making processes many important questions remain unanswered and unanswerable and medicine is weaker and poorer.

There is a need for limited and strictly defined confidentiality to protect legitimate trade secrets and individual privacy. But these should be very limited exceptions to a general principle that information within regulatory authorities should be freely available to any party requesting it. This basic principle is particularly important in the light of current trends towards semi-privatised drug regulation. Many drug regulatory agencies are increasingly financially dependent on user fees rather than public funds and this brings with it a danger of commercial pressure and conflict of interest. Openness brings with it accountability and is the best antibody both to corruption and inefficiency. A culture of openness inspires trust, encourages participation and protects conscientious individuals.

The adverse effects of excessive secrecy can take many forms. Important knowledge is buried in confidential files thus impeding scientific progress and making it harder to identify and understand risks associated with drugs. Secrecy acts as a disguise to malpractice and dishonesty and facilitates the suppression of unfavourable data. As Charles Medawar writes in his paper: "secrecy encourages poor practice, precisely because it tends to deprive the uninformed even of knowledge of the limitations

\footnotetext{
${ }^{1}$ International Working Group on Transparency and Accountability in Drug Regulation convened by the Dag Hammarskjöld Foundation and Health Action International. Uppsala, Sweden, 11-14 September, 1996.
} 
of what they know. That is an especially serious matter in medicine, where the greatest mistakes are probably made not because doctors do not know enough, but because too often they behave as if they do". Secrecy also creates a climate of distrust and suspicion in which panic and alarm can breed easily.

In recent years there has been a gradual and often reluctant acceptance of the fact that democracy demands accountability and transparency; the Treaty of Maastricht commits the EU to transparency, and "open government" is becoming an essential catch phrase for the politician. This trend has been helped along by shocking examples of the problems which secrecy can conceal. In Japan secrecy was a shield for incompetence in relation to contaminated blood products. In 1992 the former head of the Italian Medicines Division and President of the European CPMP was arrested and charged with accepting a small fortune in bribes and gifts in return for speeded up procedures, favourable price deals and changed indications. Many of the major companies were involved in this scandal and although the charges involved corruption on a national scale there were many questions asked about the immunity of European agencies and few were convinced by the reassurance that the problem was essentially an Italian one. It seems unlikely that corruption on this scale could have gone unchecked in a more open climate where the background to decisions would have been published and public.

In Europe, after the defeat of the UK Medicines Bill which would have put an end to the extraordinary secrecy which surrounds medicines regulation in Britain, people have looked to the new European Medicines Evaluation Agency to break the mould of secrecy and concealment. The EMEA does publish European Public Assessment Reports and these do give some information but fall far short of what is needed. The International Society of Drug Bulletins identified serious shortcomings including:

- lack of standardised format;

- lack of information in the content;

- weakness of clinical aspects in scientific discussion;

- difficulty in identifying which trials the CPMP had examined;

- lack of clarity in the interpretation of trial data;

- general lack of transparency.

There are countries which operate with a considerable degree of openness; the United States maintains an admirable tradition of regarding information in general as public and this principle is enshrined in a fairly comprehensive Freedom of Information Act. In Norway and Sweden much more information is made available than in most other European countries. These systems seem to work well and are respected internationally but it would seem that few countries dare to follow and develop these good examples. In Japan scandals surrounding the suppression of information about contaminated blood have led to public and political support for proposed Freedom of Information legislation. It would be a tragedy if the call for openness and accountability is only heard in the wake of scandal and suffering.

Developments in medical science, the increasing role of market forces, and a climate of personal responsibility in health all make it imperative that we draw back the veil of secrecy over medicine and concentrate on regulation which is unashamedly in the public interest. The message which emerges from these articles is one which we should not ignore: openness and accountability are preconditions for responsible and democratic decision making, in medicine as much as in other areas. Those involved in drug regulation cannot properly serve the interests of those who use medicines if they are not subject to public scrutiny. Blind faith is not an appropriate basis for developing informed confidence. 